\title{
The National Ignition Facility: Status and Plans for Laser Fusion and High- Energy-Density Experimental Studies
}

E. Moses, and C.R. Wuest

This article was submitted to the $2^{\text {nd }}$ International Atomic Energy Technical Meeting on Physics and Technology of Inertial Fusion Energy Targets and Chambers, San Diego, California, June 6, 2002

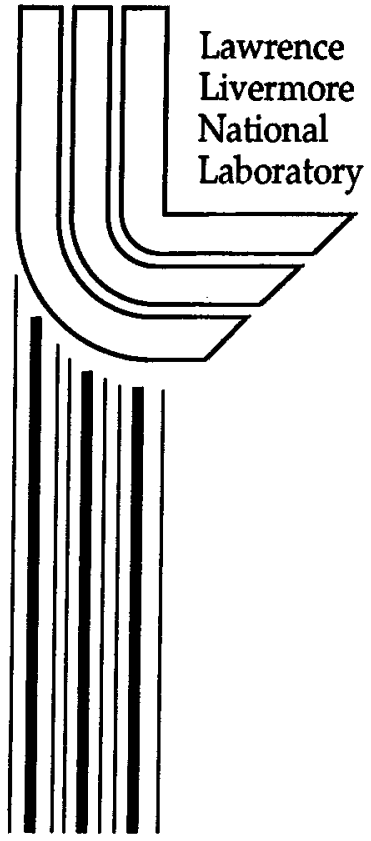

October 16, 2002 


\section{DISCLAIMER}

This document was prepared as an account of work sponsored by an agency of the United States Government. Neither the United States Government nor the University of California nor any of their employees, makes any warranty, express or implied, or assumes any legal liability or responsibility for the accuracy, completeness, or usefulness of any information, apparatus, product, or process disclosed, or represents that its use would not infringe privately owned rights. Reference herein to any specific commercial product, process, or service by trade name, trademark, manufacturer, or otherwise, does not necessarily constitute or imply its endorsement, recommendation, or favoring by the United States Government or the University of California. The views and opinions of authors expressed herein do not necessarily state or reflect those of the United States Government or the University of California, and shall not be used for advertising or product endorsement purposes.

This is a preprint of a paper intended for publication in a journal or proceedings. Since changes may be made before publication, this preprint is made available with the understanding that it will not be cited or reproduced without the permission of the author.

This report has been reproduced directly from the best available copy.

Available electronically at http://www.doc.gov/bridge

Available for a processing fee to U.S. Department of Energy And its contractors in paper from

U.S. Department of Energy

Office of Scientific and Technical Information

P.O. Box 62

Oak Ridge, TN 37831-0062

Telephone: (865) 576-8401

Facsimile: (865) 576-5728

E-mail: reports@adonis.osti.gov

Available for the sale to the public from

U.S. Department of Commerce

National Technical Information Service

5285 Port Royal Road

Springfield, VA 22161

Telephone: (800) 553-6847

Facsimile: (703) 605-6900

E-mail: orders@ntis.fedworld.gov

Online ordering: $\mathrm{http}: / /$ www.ntis.gov/ordering.htm

OR

Lawrence Livermore National Laboratory

Technical Information Department's Digital Library

http://www.llnl.gov/tid/Library.html 
The National Ignition Facility:

Status and Plans for Laser Fusion and

High-Energy-Density Experimental Studies

Edward I. Moses

Craig R. Wuest

Lawrence Livermore National Laboratory

P.O. Box 808 L-466

Livermore, CA 94551

Total Pages: 27

Total Tables: 0

Total Figures: 8

(925) 423-9624 (voice)

(925) 423-5957 (fax)

moses1@1lnl.gov

wuest@llnl.gov 


\begin{abstract}
The National Ignition Facility (NIF), currently under construction at the University of California's Lawrence Livermore National Laboratory, is a stadium-sized facility containing a 192-beam, 1.8-Megajoule, 500-Terawatt, 351-nm laser system and a 10meter diameter target chamber with room for nearly 100 experimental diagnostics. NIF is being built by the National Nuclear Security Administration and when completed will be the world's largest laser experimental system, providing a national center to study inertial confinement fusion and the physics of matter at extreme energy densities and pressures. NIF will provide 192 energetic laser beams that will compress small fusion targets to conditions where they will ignite and burn, liberating more energy than is required to initiate the fusion reactions. NIF experiments will allow the study of physical processes at temperatures approaching 100 million $\mathrm{K}$ and 100 billion times atmospheric pressure. These conditions exist naturally only in the interior of stars and in nuclear weapons explosions. In the course of designing the world's most energetic laser system, a number of significant technology breakthroughs have been achieved. Research is also underway to develop a shorter pulse capability on NIF for very high power and extreme electromagnetic field research and applications. We discuss here the technology challenges and solutions that have made NIF possible, along with enhancements to NIF's design that could lead to near-exawatt power levels.
\end{abstract}




\section{Introduction}

The National Ignition Facility (NIF) under construction at the Lawrence Livermore National Laboratory (LLNL) will be a U. S. Department of Energy and National Nuclear Security Administration (NNSA) national center to study inertial confinement fusion and the physics of extreme energy densities and pressures. It will be a vital part of the NNSA Stockpile Stewardship Program (SSP), which ensures the reliability and safety of U. S. nuclear weapons. In NIF, up to 192 extremely powerful laser beams will compress deuterium-tritium fusion targets to conditions where they will ignite and burn, liberating more energy than is required to initiate the fusion reactions. NIF experiments will allow the study of physical processes at temperatures approaching 100 million $\mathrm{K}$ and 100 billion times atmospheric pressure. These conditions exist naturally only in the interior of stars and in nuclear weapons explosions. (1-3)

\section{A Description of NIF}

The National Ignition Facility is shown schematically in Figure 1. (4) NIF consists of a number of sub-systems including amplifier power conditioning modules, the injection laser system consisting of the master oscillator and preamplifier modules, the main laser system along with its optical components, the switchyards, and the target chamber and its experimental systems. The entire laser system, switchyards, and target area is housed in an environmentally controlled building. An integrated computer control system is located in the core of the facility to monitor, align, and operate the more than 60,000 control points required for NIF's operation. A large cleanroom facility, the Optics Assembly Building is located at one end of NIF for assembling and installing the precision optical and opto-mechanical components that make up the NIF laser system. On 
the opposite end of the facility the Diagnostics Building houses experimenters, a data acquisition system, and target preparation and storage areas.

NIF's laser system, the heart of the facility, is comprised of 192 high-power laser beams. For inertial fusion studies the laser beams will produce a nominal 1.8 million joules (approximately 500 trillion watts of power for 3 nanoseconds) of laser energy in the near-ultraviolet ( 351 nanometer wavelength) onto a target. This is approximately 50 times the energy available in the Nova laser, which was operated at LLNL between 1983 and 1999 and Omega Laser at the University of Rochester's Laboratory for Laser Energetics. NIF is capable of providing a range of beam energies and powers for highenergy density experimental and diagnostic backlighter applications

Figure 2 schematically shows one of the 192 laser beams, detailing the key technologies that make NIF possible. A NIF laser beam begins with a very modest nanojoule energy pulse from the master oscillator and a diode-pumped fiber amplifier system that can provide a variety of pulse shapes suitable for a wide range of experiments, from complex high contrast pulses for ICF implosions to high-energy extended pulses. The master oscillator pulse is shaped in time and then transported to preamplifier modules (PAMs) for amplification and beam shaping. Each PAM first amplifies the pulse by a factor of one million (to about one millijoule) and then boosts the pulse once again by a factor of 20,000 , this time to a maximum of 10 joules, by passing the beam four times through a flashlamp-pumped amplifier. There are a total of 48 PAMs on NIF, each feeding a "quad" of four laser beams.

From the PAM the laser beam next enters the main laser system, which consists of two large amplifier units - the power amplifier, and the multi-pass or main amplifier. 
These amplifier systems are designed to efficiently amplify the nominal three joule input pulse from the PAM to the mission-required power and energy, maintaining the input beam's spatial, spectral, and temporal characteristics. The amplifiers, with 16 glass slabs per beam, are arranged with 11 slabs in the main amplifier section and five slabs in the power amplifier section (the power amplifier can actually accommodate 7 slabs per beam if necessary for future applications). Together, even though of relatively low gain $\left(\sim \times 10^{4}\right)$, these amplifiers provide $99.9 \%$ of NIF's power and energy. The amplifiers use 42 kilogram slabs, measuring $46 \mathrm{~cm} \times 81 \mathrm{~cm} \mathrm{x} 3.4 \mathrm{~cm}$, of neodymium-doped phosphate glass set vertically on edge at Brewster's angle to minimize reflective losses in the laser beam. The slabs are stacked four high and two wide to accommodate a "bundle" of eight laser beams (Figure 3).

The slabs are surrounded by vertical arrays of flashlamps, measuring $180 \mathrm{~cm}$ in length. A total of 7680 flashlamps and 3072 glass slabs are required for NIF's 192 laser beams. Each flashlamp is driven by 30,000 joules of electrical energy. The intense white light from the flashlamps excites the neodymium in the laser slabs to provide optical gain at the primary 1.06 micron infrared wavelength of the laser. Some of the energy stored in the neodymium is released when the laser beam passes through the slab. Advances in glass amplifier technology allow NIF to operate with less than twice the number of flashlamps than Nova even though the laser system will produce 60 times more output energy. The flashlamps will be cooled between shots, along with the amplifier slabs, using nitrogen gas. NIF will be able to shoot once every 8 hours; a shot rate enhancement program funded by our collaborators from the United Kingdom is working to increase the cooling rate so that NIF can be fired once every four hours. 
The NIF amplifiers receive their power from the Power Conditioning System (PCS), which consists of the highest energy array (about 400 megajoules) of electrical capacitors ever assembled. The system's design is the result of a collaboration between Sandia National Laboratories in Albuquerque, LLNL, and industry. The PCS will occupy four capacitor bays adjacent to each laser bay as shown in Figure 1.

Each PCS module is configured with eight, 20-capacitor modules delivering 1.7 megajoules per module that power the flashlamps for one beam. The NIF PCS delivers electrical energy nearly 10 times cheaper per joule than on Nova. Recent tests on a prototype PCS and flashlamp system have now fired 14000 times at a rate of 1200 shots per month, corresponding to one half of NIF's projected 30-year lifetime. Nine power conditioning modules are now installed and delivering electrical power to flashlamps in Laser Bay 2 in preparation for the first four laser beams to be commissioned later this year.

A key component in the laser chain is an optical switch called a plasma-electrode Pockels cell (PEPC), which allows the beam to pass four times through the main amplifier cavity. This device uses electrically induced changes in the refractive index of an electro-optic crystal, made of potassium dihydrogen phosphate (KDP). When combined with a polarizer, the PEPC allows light to pass through or reflect off the polarizer. The PEPC will essentially trap the laser light between two mirrors as it makes four one-way passes through the main amplifier system before being switched out to continue its way to the target chamber. The PEPC consists of thin KDP plates sandwiched between two gas-discharge plasmas. The plasma density is approximately $10^{12} / \mathrm{cm}^{3}$ and there is no effect on the laser beam passing through the cell, yet the plasmas 
form sufficiently conducting electrodes, allowing the entire surface of the thin crystal plate to charge electrically in about 100 nanoseconds so the entire beam can be switched efficiently. Figure 2 shows a four-cell PEPC (optical switch) in operation that will be oriented vertically in a single unit when inserted into NIF's beampath.

There are many other parts of NIF that are not covered in detail here. All major laser components are assembled in clean, pre-aligned modules called line-replaceable units or LRUs. These LRUs contain laser optics, mirrors, lenses, and hardware such as pinhole filter assemblies. All LRUs are designed to be robotically installed into NIF's beampath infrastructure system, the exoskeleton of NIF, while maintaining the high level of cleanliness required for proper laser operation. Figure 4 shows a photograph of an automated guided vehicle with a portable clean room positioned underneath a main amplifier section of NIF and installing a laser glass slab LRU into the beampath. The installation, integration, and commissioning of the beampath infrastructure at the required cleanliness levels has been successfully accomplished for approximately $50 \%$ of the system and is progressing rapidly.

The NIF target area consists of the 10-meter diameter high-vacuum target chamber shown in Figure 5. The target chamber contains a large number of laser entry ports as well as over 100 ports for diagnostic instrumentation and target insertion. Each laser entry port allows a quad of laser beams to be focused to the center of the target chamber through a final optics assembly (FOA). The FOA is a precision optical assembly containing optics to provide a variety of beam profiles on target, KDP and deuterated KDP plates to convert the infrared laser light into the ultraviolet, the final focus lens, 
debris shields and vacuum gate valve for each beam. In Fig. 5 an FOA is simulated in the position where the first four laser beams of NIF will be directed into the target chamber.

The NIF target chamber and final focusing system has been designed with maximum flexibility for experimental users. During initial operation, NIF is configured to operate in the "indirect drive" configuration, which directs the laser beams into two cones in the upper and lower hemispheres of the target chamber. This configuration is optimized for illuminating the fusion capsule mounted inside cylindrical hohlraums using $\mathrm{x}$-rays generated from the hot walls of the hohlraum to implode the capsule. NIF can also be configured in a "direct drive" arrangement of beams, by moving some quads of beams from the upper and lower hemispheres into a more symmetric arrangement of beams. Direct drive ignition requires better energy and power balance between laser beams and better beam smoothing and focusing but some think this configuration may ultimately be more attractive for producing a viable power production plant because of the higher gain available.

Figure 6 shows the initial configuration of diagnostics to be fielded on the NIF target chamber during the early stages of experimental operations soon after first light. Diagnostics can be located in a variety of positions but initially will be placed around the equator of the target chamber or near the top pole.

\section{NIF Project Status}

NIF is currently over five years into its construction. Figure 7 shows a recent aerial photograph of the NIF site. The conventional building construction was completed in September 2001. The 8,000 square foot class-100 clean room Optics Assembly Building has commissioned all of its LRU assembly, handling, and transport equipment. 
Both large laser bays are operating under class-100,000 clean room protocols. In October 2001 the first 48-beam clean infrastructure was completed and in June 2002 the second 48-beam clean infrastructure was assembled. Currently over one half of NIF's beampath infrastructure is in place.

In October 2001 the first laser light from NIF's master oscillator was generated in the fully operational master oscillator room located in the central core of the NIF building. This master oscillator has been continuously running and has demonstrated the required pulse shaping stability and accuracy for high contrast ignition pulses and other types of laser pulses that are of interest to NIF experimenters. In June 2002 the first preamplifier module was installed in the Laser Bay and has successfully amplified master oscillator pulses to the joule level.

The NIF Project is now entering the installation and commissioning phase. First light, which is defined as the first quad of four laser beams focused to target chamber center, is scheduled for June 2004; however we are working hard to achieve this important milestone as early as possible. Full completion of all 192 laser beams is scheduled for September 2008. In the time between first light and project completion, approximately 1500 experiments are planned in support of the Stockpile Stewardship Program, inertial confinement fusion, high energy density physics, weapons effects, inertial fusion energy, and basic science. (5-7)

After project completion, NIF is expected to provide approximately 750 shots per year for a wide variety of experimental users. Recently NIF was designated as a National User Facility with the support of the NNSA Office of Defense Programs. A National 
User Support Office is now being put in place to provide the necessary interface between the user communities and the national NIF Program.

\section{Conclusions and Future Directions}

The National Ignition Facility has come a long way since the first DOE critical decision in January 1993 affirmed the need for NIF and authorized the conceptual design process. In that time NIF has met every scientific and technical challenge and is now in the final stages of design and construction prior to commencing installation of the 192 laser beams.

Research is also beginning on developing picosecond pulse capability on NIF to explore applications for high power $\mathrm{x}$-ray backlighters, fast ignition concepts, and extreme field science. NIF's flexible, modular design allows a number of different technologies for pulse injection and final high power optics to be fielded and tested.

Rapid advances in the science of high-intensity laser-matter interactions have revealed new horizons for research. Related swift technological progress has also made possible the adaptation of high-energy lasers to generate pulses in the picosecond domain with powers exceeding one petawatt. There is a worldwide surge of scientific activity in . this new field and it has become apparent that NIF has new potential for programmatic science requiring the generation of high-energy petawatt (HEPW) pulses, 1-2 orders of magnitude in energy beyond the $0.5 \mathrm{~kJ}$ of the first petawatt-class laser pioneered using the Nova Laser at LLNL.

Figure 8 shows how NIF could be configured to accommodate a pulse compression and grating decompression system in order to achieve HEPW pulses. In the longer term, the available megajoule energy of NIF together with the amplification 
bandwidth of neodymium glass defines an ultimate power capability approaching the exawatt, or 1,000-petawatt level. A new Petawatt Initiative supported by the National Nuclear Security Administration at the three main high energy laser facilities (LLNL, the Laboratory for Laser Energetics at the University of Rochester, and Sandia National Laboratories) seeks to exploit the potential of HEPW lasers and promises exciting new science for this National Program.

While full completion of all 192 laser beams is scheduled for September 2008, by 2004 this unique facility will already be providing the first glimpses of conditions heretofore only found in the most extreme environments. This will be done under repeatable and well-characterized laboratory conditions for the benefit of national security and science. (ㅁ)

\section{Acknowledgments}

The author would like to express his appreciation to the many people, institutions, and industrial partners that are diligently working to provide the National Ignition Facility for our nation. This work was performed under the auspices of the U.S. Department of Energy by the University of California, Lawrence Livermore National Laboratory under contract W-7405-Eng-48.

\section{References}

1. J. Lindl, Inertial Confinement Fusion: The Quest for Ignition and Energy Gain Using Indirect Drive, Springer-Verlag (1998).

2. "Laboratory Microfusion Capability Phase-II Study," prepared by Interscience, Inc. for the Inertial Fusion Division Office of Research and Advanced Technology, ISITM9005281, May 31, 1990. 
3. "Solid State Lasers for Application to Inertial Confinement Fusion (ICF)," W. F. Krupke, ed., Proc. SPIE 2633 (1995).

4. C. B. Tarter, "Inertial Fusion and Higher Energy Density Science in the United States," Proc. 2001 Conf. On Inertial Fusion Science and Applications (IFSA 2001), K. A. Tanaka, D. D. Meyerhofer, J. Meyer-ter-Vehn, eds., Elsevier (2002).

5. S. Haan, et al., "Update On Target Design for the National Ignition Facility," Proc. 2001 Conf. On Inertial Fusion Science and Applications (IFSA 2001), K. A. Tanaka, D. D. Meyerhofer, J. Meyer-ter-Vehn, eds., Elsevier (2002).

6. B. Remington, "High Energy Density Astrophysics in the Laboratory," Proc. 2001 Conf. On Inertial Fusion Science and Applications (IFSA 2001), K. A. Tanaka, D. D. Meyerhofer, J. Meyer-ter-Vehn, eds., Elsevier (2002).

7. "High-Energy-Density Physics Study Report," prepared by the National Nuclear Security Administration Office of Defense Programs, April 6, 2001.

8. For more information on the NIF Project please visit our web site at http://www.llnl.gov/nif 
Fig. 1. Schematic view of the National Ignition Facility showing the main elements of the laser system. The 10-meter diameter target chamber sets the scale for the facility. 
The National Ignition Facility: Status and Plans for Laser Fusion and High-Energy-Density Experimental Studies, Edward I. Moses, Craig R. Wuest

\section{Figure 1}

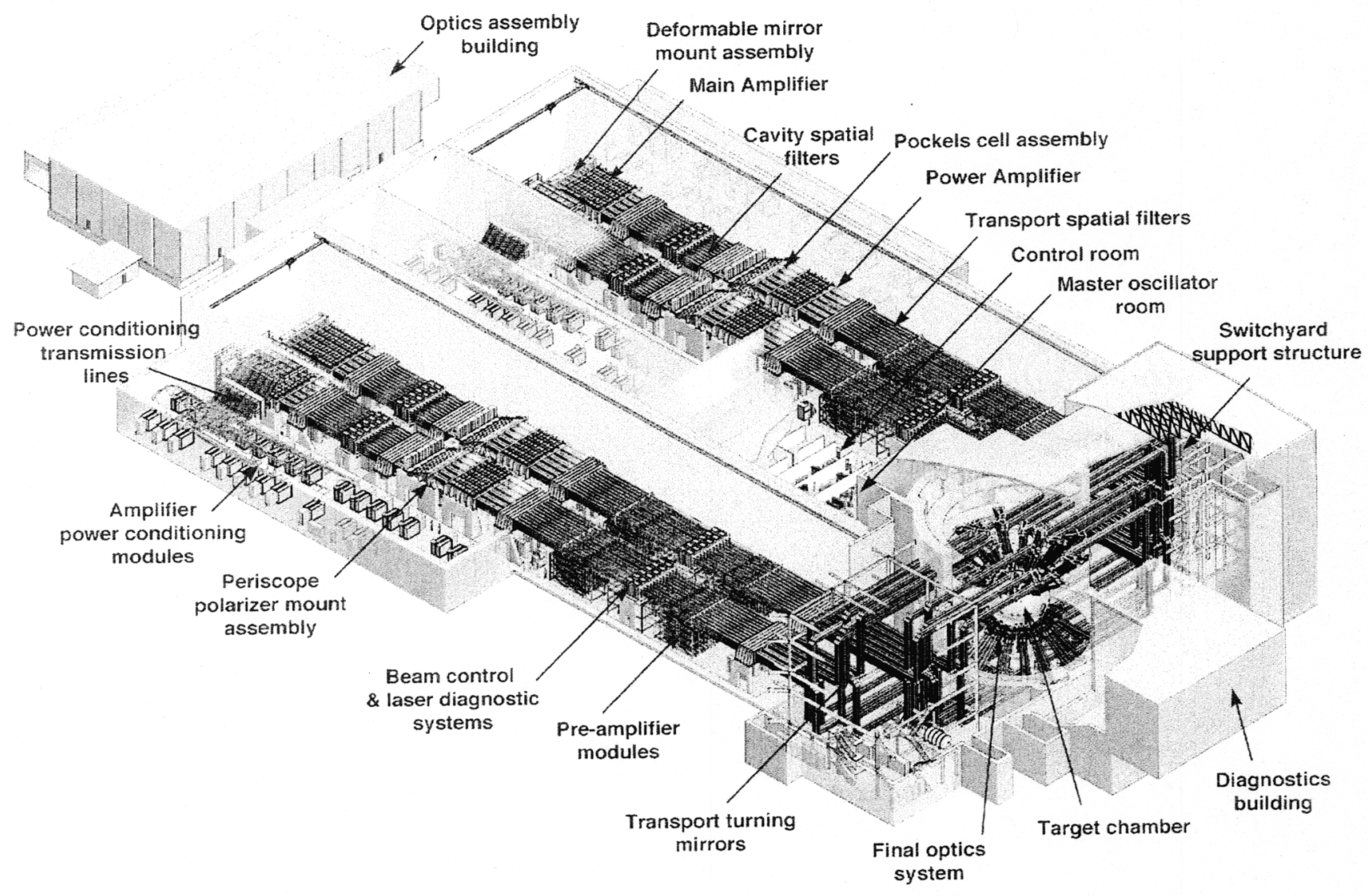


Fig. 2. Schematic representation of a NIF laser beam line highlighting some of the key technology developments. 
The National Ignition Facility: Status and Plans for Laser Fusion and High-Energy-Density Experimental Studies, Edward I. Moses, Craig R. Wuest

\section{Figure?}

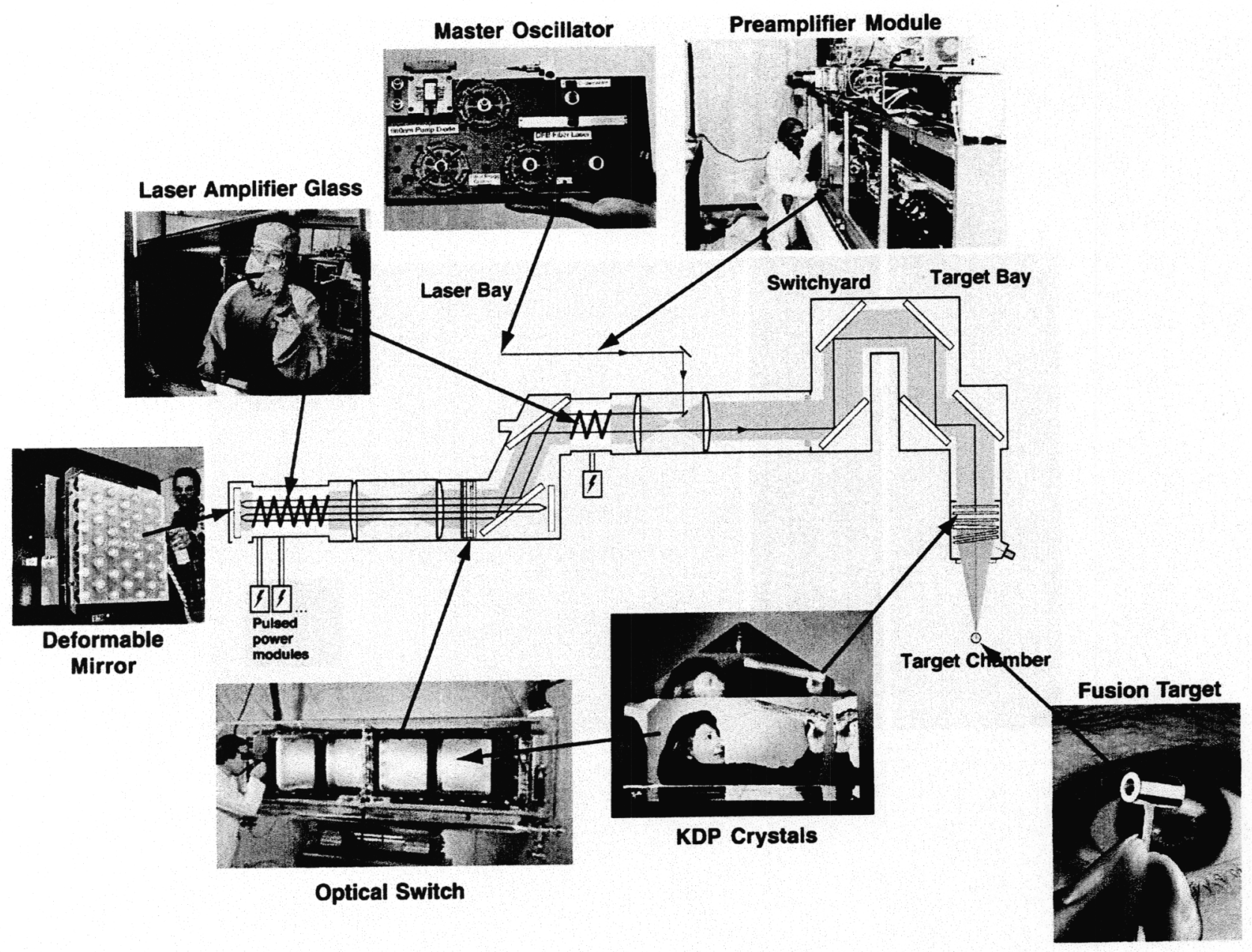


Fig. 3. The photograph on the left shows a laser amplifier glass slab line-replaceable unit assembled in the NIF Class-100 Optics Assembly Building. Laser glass slab LRUs are assembled into amplifier housings that also contain flashlamps used to pump the glass, shown in a CAD cut-away of a NIF amplifier on the right. 
The National Ignition Facility: Status and Plans for Laser Fusion and High-Energy-Density Experimental Studies, Edward I. Moses, Craig R. Wuest

\section{Figure 3}
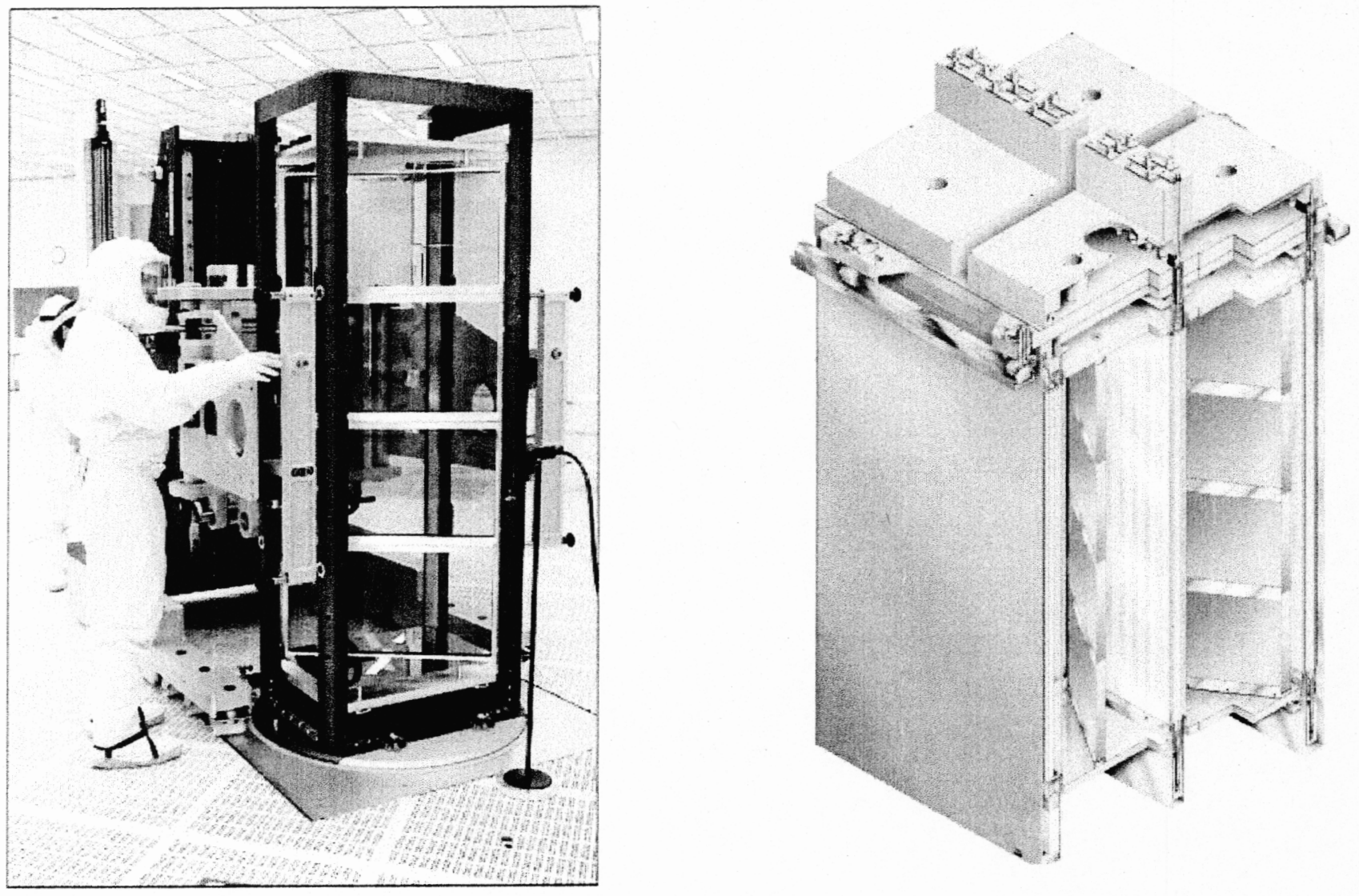
Fig. 4 Automated guided vehicle with portable clean room installing a glass slab LRU into the main laser amplifier. 
The National Ignition Facility: Status and Plans for Laser Fusion and High-Energy-Density Experimental Studies, Edward I. Moses, Craig R. Wuest

Figure 4

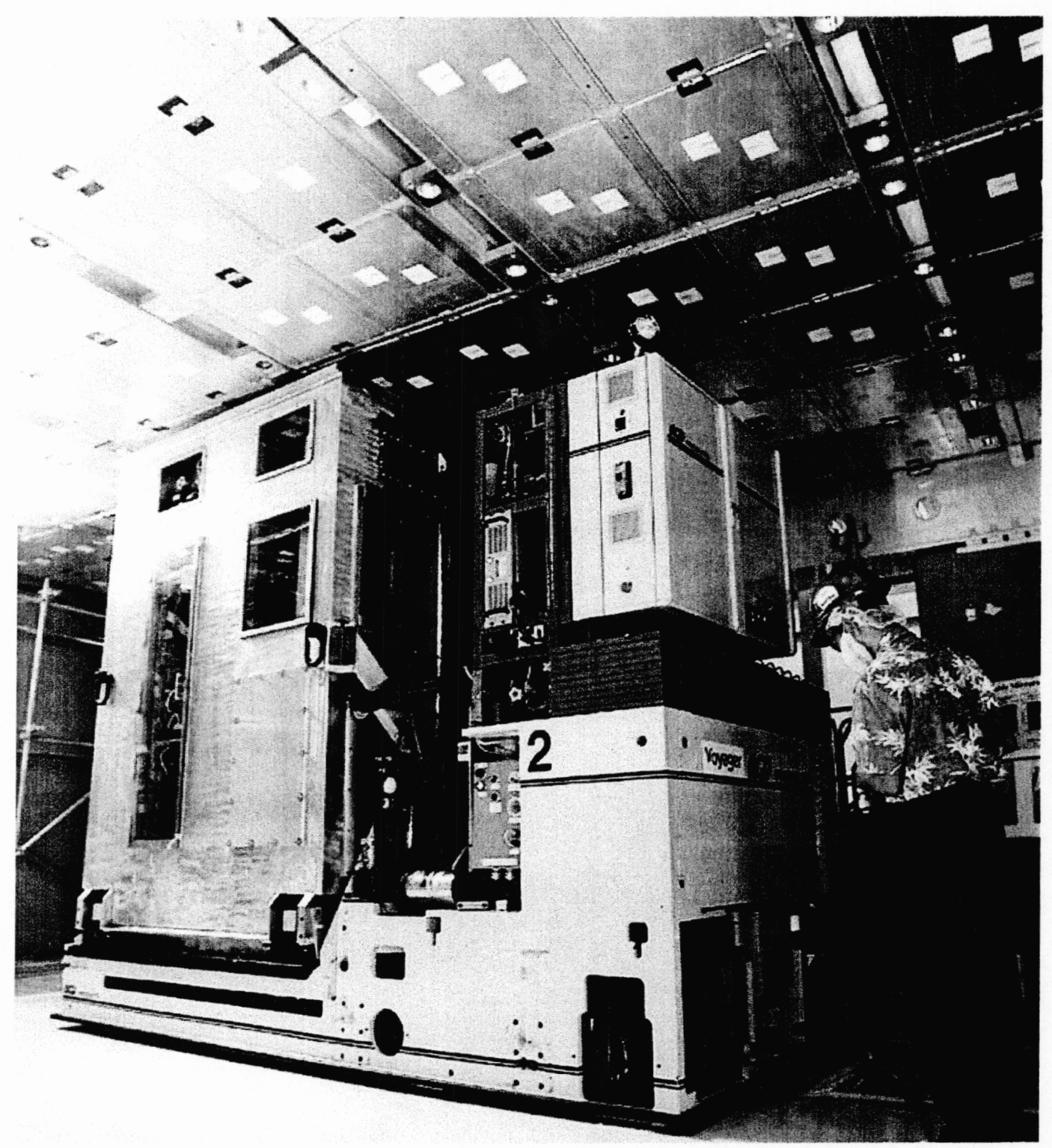


Fig. 5 NIF's 10-meter diameter target chamber is shown in this composite photograph. A final optics assembly (FOA) is simulated in the position where NIF's first four laser beams will be directed into the target chamber. The actual FOA will be installed onto the target chamber in late 2002. 
The National Ignition Facility: Status and Plans for Laser Fusion and High-Energy-Density Experimental

Studies, Edward I. Moses, Craig R. Wuest

Figure 5

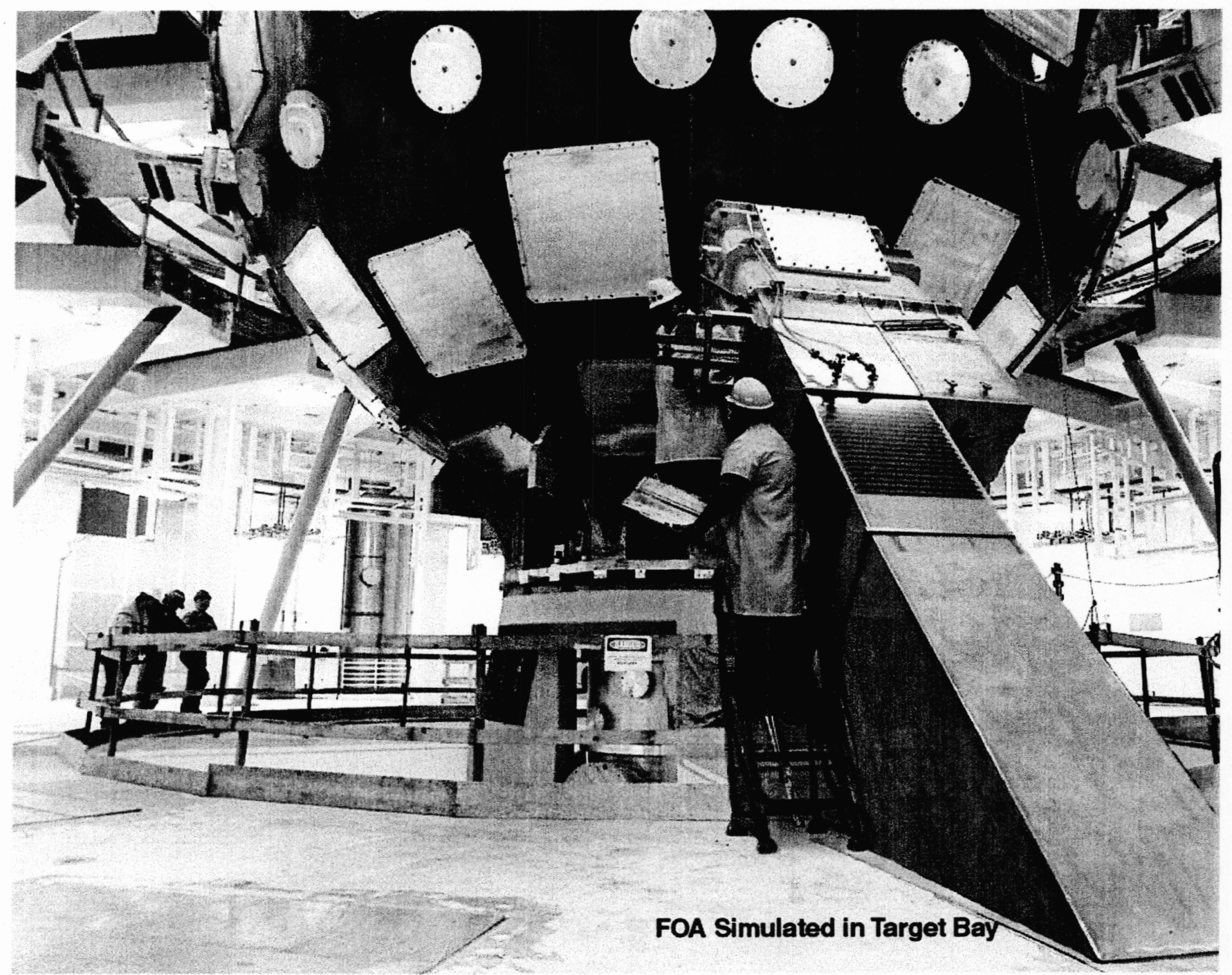


Fig. 6 Cut-away view of the NIF Target Chamber showing the layout of target positioner and Target Alignment System, along with the first diagnostics to be fielded on NIF. The VISAR (Velocity Interferometer System for Any Reflector) is a vertically oriented visible light laser radar system used to measure velocities in materials experiments. 
The National Ignition Facility: Status and Plans for Laser Fusion and High-Energy-Density Experimental

Studies, Edward I. Moses, Craig R. Wuest

Figure 6

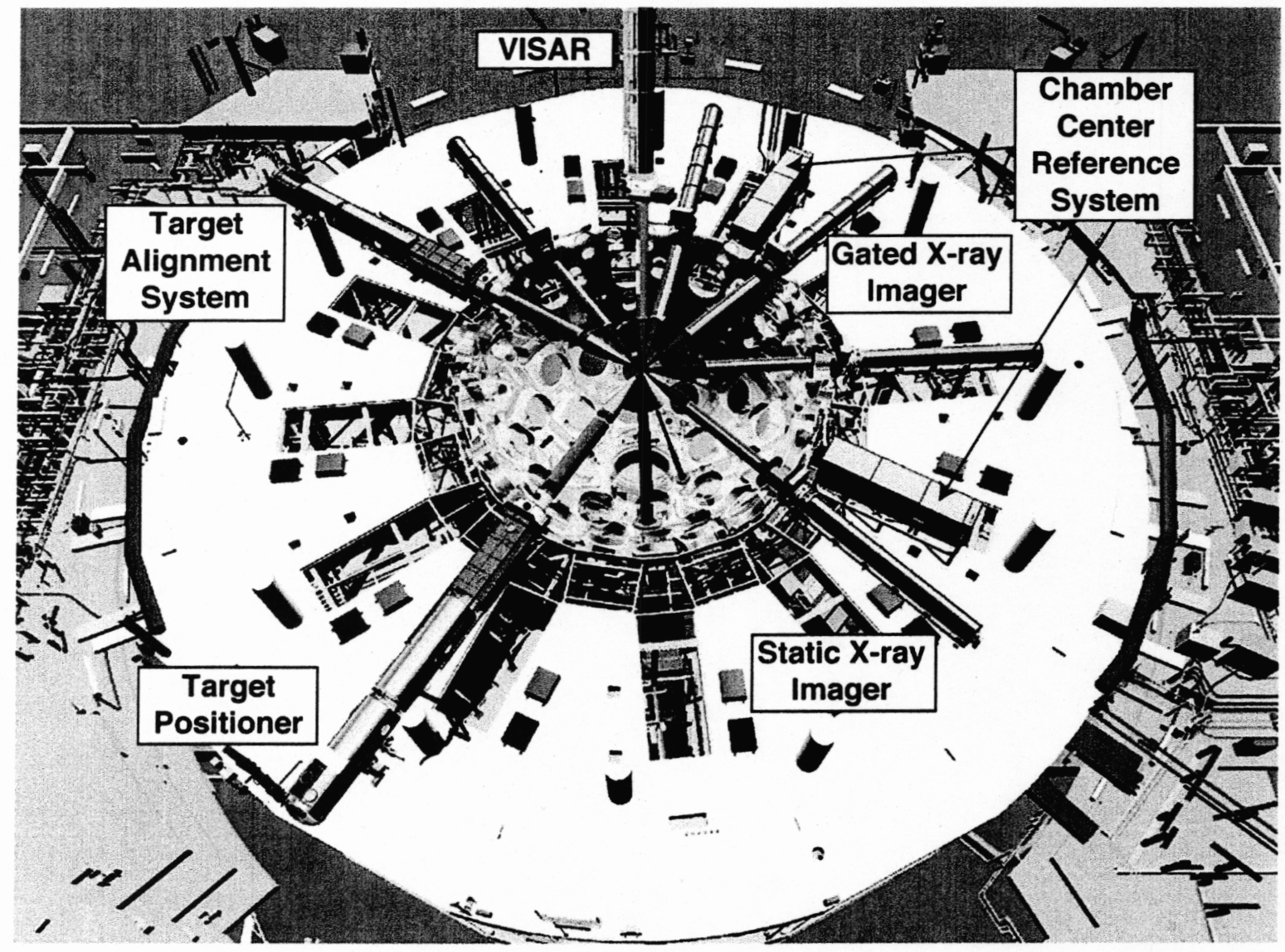


Fig. 7. Aerial photograph of the NIF site at Lawrence Livermore National Laboratory taken in October 2001 soon after the completion of the conventional facilities. 
The National Ignition Facility: Status and Plans for Laser Fusion and High-Energy-Density Experimental Studies, Edward I. Moses, Craig R. Wuest

Figure 7

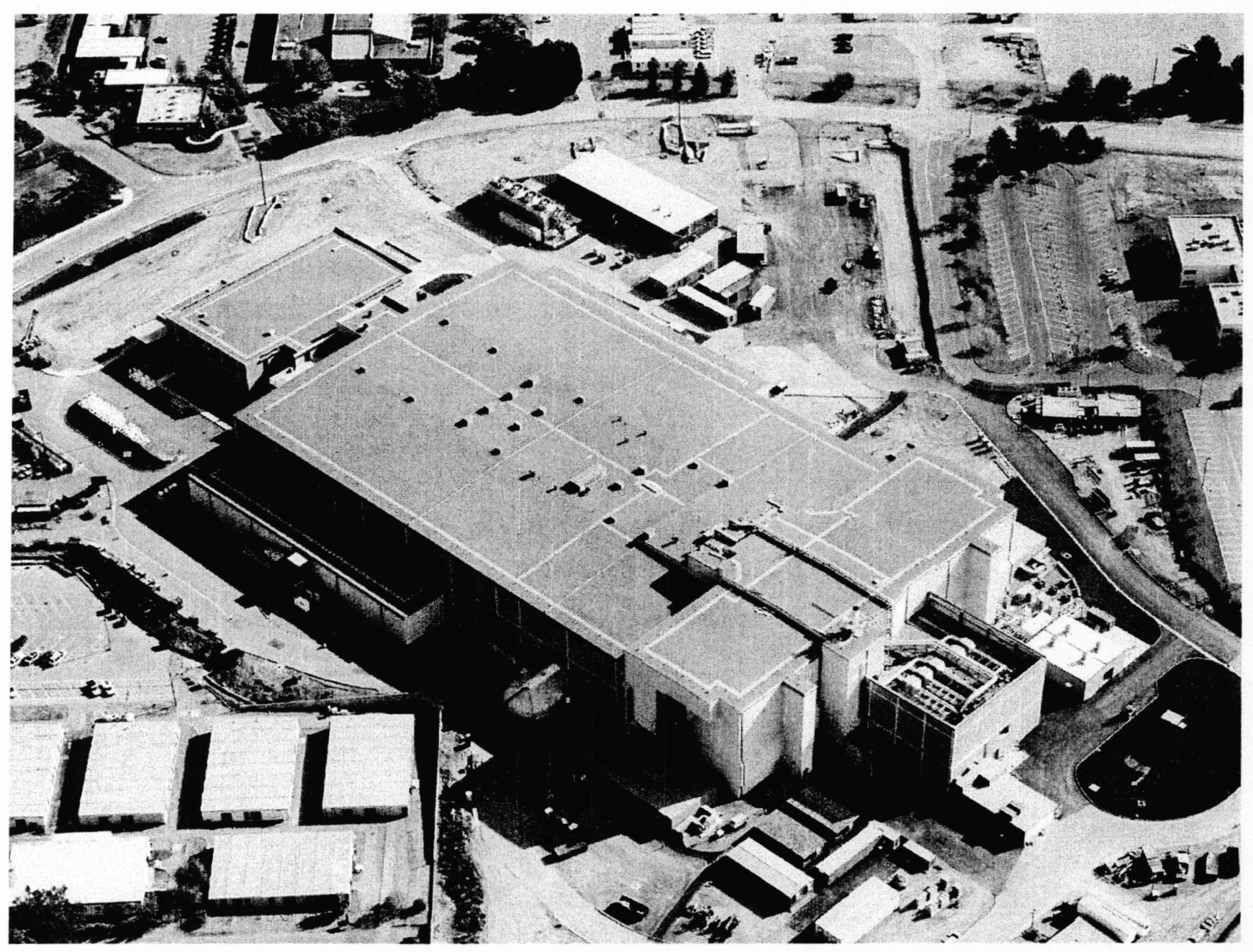


Fig. 8. Schematic representation of a short-pulse beamline concept for NIF. The front end is modified using a chirped fiber Bragg grating stretcher and a compressor utilizing thin transmission grating technology is placed in the beamline prior to the final optics assembly at the target chamber. This concept provides 5-20 picosecond pulses corresponding to petawatt power levels in a single NIF beamline. 
The National Ignition Facility: Status and Plans for Laser Fusion and High-Energy-Density Experimental Studies, Edward I. Moses, Craig R. Wuest

Figure 8

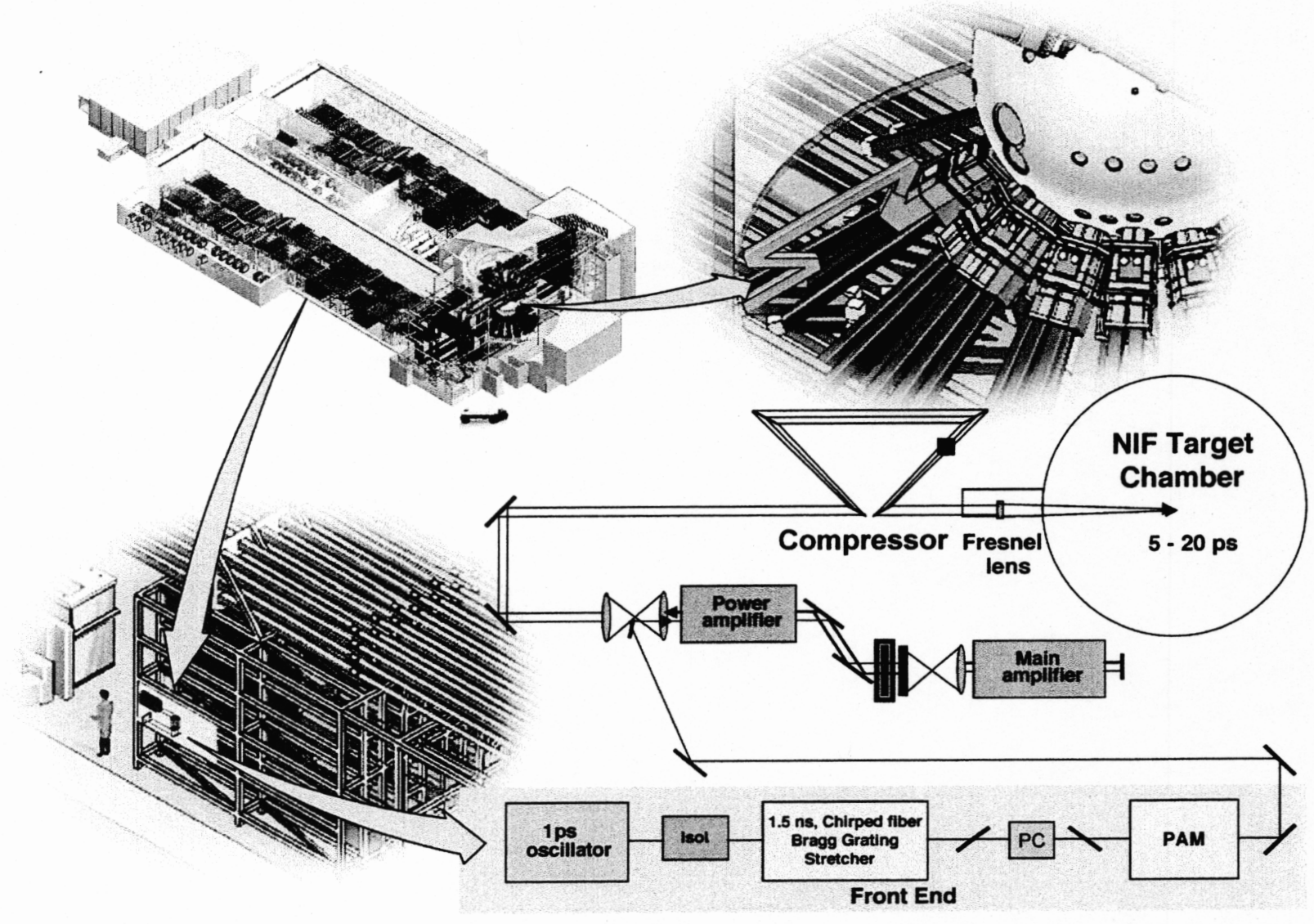

